\title{
Dynamic Positioning System of Semi- Submersible Platform Using Fuzzy Control
}

and C. K. Morooka

Department of Petroleum Engineering State University of Campinas Caixa Postal 6052

13083-970 Campinas, SP. Brazil marcioy@dep.fem.unicamp.br morooka@dep.fem.unicamp.br
The purpose of this paper is the study of fuzzy control applied to a Dynamic Positioning System (DPS) of semi-submersible platforms. A numerical simulator program in time domain was coded using mathematical models of the floating platform dynamics and the external forces (wind, current, wave and thruster) that act on the platform. Subsequently, a fuzzy controller applied to DPS was developed. The Fuzzy controller and the ProportionalIntegral-Derivative (PID) controller were then subjected to the same environmental conditions in order to compare their performance.

Keywords: Offshore petroleum, ocean waves, floating drilling platform, and dynamic positioning system

\section{Introduction}

For oil and gas offshore Exploration and Production (E\&P) operations in waters deeper than 300 meters, floating platforms such as Drillships and Semi-Submersible Platforms are used. These vessels must be kept stationary at a desired location (reference) to accomplish their offshore E\&P tasks. Therefore, the platform must have means of producing forces and momenta to counterbalance environmental forces (wind, currents and waves) in order to keep it at the desired location.

In the most common case, the platform is equipped with anchor lines. A mooring system usually has 8 to 12 anchor lines for each platform. However, in water depths deeper than 1000 meters, a mooring system becomes uneconomic or impracticable.

This problem was overcome with the development of the Dynamic Positioning System (DPS). The DPS controls platform displacements in the three horizontal degrees of freedom: surge, sway and yaw. The DPS is composed of a controller, a sensor system, a thruster system, and a power system. The sensor system feeds to the controller (computer) with information about the platform positioning and environmental parameters - winds, currents and waves. The controller commands the action of thrusters, installed on the bottom of the platform hull, that generate the forces and momenta needed to counteract the environmental forces and thus keep the platform at the reference. The controller keeps the platform within a tolerance radius of about $2 \%$ to $6 \%$ of the water depth, depending on the surface equipment and the operation to be executed. Furthermore, a DPS can also assist a moored platform as, for example, changing its head to minimize the environmental loads (Tannuri et al., 2001).

The numerical simulator developed for this paper had only one degree of freedom - sway, and was intended to be used in the comparison between DPS equipped with different types of fuzzy controllers and with a Proportional-Integral-Derivative (PID) controller. These different DPS controllers were applied to the same environmental conditions in order to assess their performances.

\section{Nomenclature}

$$
\begin{aligned}
& A=\text { total frontal area, } \mathrm{m}^{2} \\
& \mathrm{a}=\text { added mass as in function of frequency, dimensionless } \\
& \mathrm{B}=\text { viscous damping coefficient, dimensionless } \\
& \mathrm{b}=\text { damping coefficient as in function of frequency, } \\
& \quad \text { dimensionless } \\
& \mathrm{C}_{\mathrm{D}}=\text { drag coefficient, dimensionless }
\end{aligned}
$$

Paper accepted July, 2005. Technical Editor: Atila P. Silva Freire. $\mathrm{c}=$ hydrostatic restoration, dimensionless

$\mathrm{E}=$ thrust delivered, $\mathrm{N}$

$\mathrm{E}_{\mathrm{C}}=$ command signal, $\mathrm{N}$

$\mathrm{e}=$ error signal, dimensionless

$\mathrm{H}_{\mathrm{S}}=$ significant wave height, $\mathrm{m}$

$\mathrm{h}_{1}=$ first order Volterra kernel, dimensionless

$\mathrm{h}_{2}=$ second order Volterra kernel, dimensionless

$\mathrm{H}_{1}=$ first order transfer function

$\mathrm{H}_{2}=$ second order transfer function

$\mathrm{i}=$ imaginary unit, dimensionless

$\mathrm{K}=$ impulse response function, dimensionless

$\mathrm{K}_{\mathrm{D}}=$ derivative gain, dimensionless

$\mathrm{K}_{\mathrm{I}}=$ integral gain, dimensionless

$\mathrm{K}_{\mathrm{P}}=$ proportional gain, dimensionless

$\mathrm{M}=$ Mass, $\mathrm{kg}$

$\mathrm{M}_{\mathrm{F}}=$ semantic rules, dimensionless

$\mathrm{m}=$ constant added mass, $\mathrm{kg}$

$\mathrm{R}_{\mathrm{i}}=\mathrm{i}$-fuzzy controller rules, dimensionless

$\mathrm{S}=$ specified wave spectrum, $\mathrm{m}^{2} \cdot \mathrm{s}$

$\mathrm{t}=$ time, $\mathrm{s}$

$\mathrm{T}=$ set of linguistic terms of $\mathrm{X}$, dimensionless

$\mathrm{T}_{0}=$ peak period, $\mathrm{s}$

$\mathrm{u}=$ control signal, dimensionless

$\mathrm{V}=$ wind/fluid particle velocity, $\mathrm{m} / \mathrm{s}$

$x=$ displacement, $\mathrm{m}$

$\dot{x}=$ velocity, $\mathrm{m} / \mathrm{s}$

$\ddot{x}=$ acceleration, $\mathrm{m} / \mathrm{s}^{2}$

$\mathrm{X}=$ name of the linguistic variable, dimensionless

Greek Symbols

$\alpha, \beta=$ generic input linguistic term, dimensionless $\gamma_{\mathrm{I}}=\mathrm{i}$-th output linguistic term, dimensionless

$\varepsilon_{\mathrm{I}}=\mathrm{i}$-th random phase between $0-2 \pi$, rad

$\rho=$ air/water density, $\mathrm{kg} / \mathrm{m} 3$

$\mu_{\mathrm{X}}=$ membership degree, dimensionless

$\tau=$ time constant of the thrusters, $\mathrm{s}$

$\zeta=$ wave elevation at time, $\mathrm{m}$

$\zeta_{\mathrm{I}}=$ elevation of i-th wave, $\mathrm{m}$

$\Omega=$ discourse universe of the linguistic variable

$\omega_{0}=$ peak frequency, $\mathrm{rad} / \mathrm{s}$

$\omega_{\mathrm{I}}=\mathrm{i}$-th wave frequency, $\mathrm{rad} / \mathrm{s}$

$\Delta \omega=$ frequency increment, $\mathrm{rad} / \mathrm{s}$

Subscripts

1 relative to first order

2 relative to second order

a relative to air

$\mathrm{X}$ relative to linguistic variable 


\section{Dynamic Positioning System}

The development of a DPS is a multidisciplinary problem. According to Morgan (1978), a DPS can be divided basically into 4 sub-systems (Figure 1):

Sensor system;

Controller;

Thruster system; and

Power system.

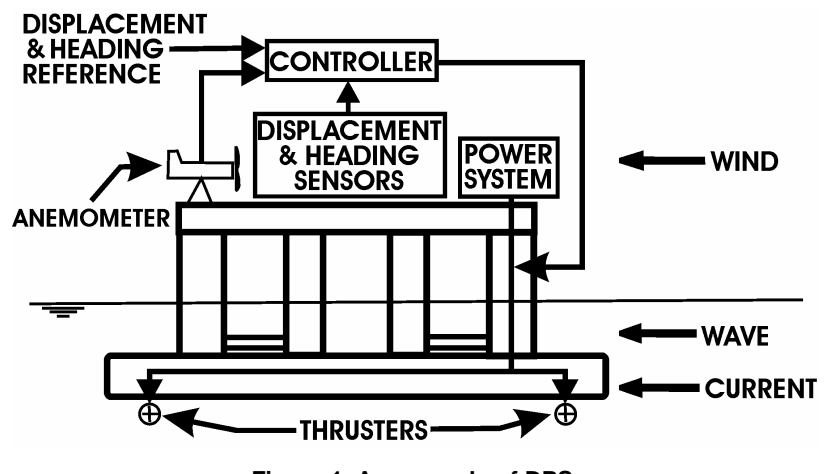

Figure 1. An example of DPS.

The sensor system is responsible for the measurement of platform displacement and environmental parameters.

There are several types of displacement measuring sensors, the most common being the Differential Global Positioning System (DGPS) and the Acoustic Position Reference System. DGPS uses the satellite-based GPS navigation system developed by the U.S. Department of Defense and removes the error in the GPS signal by first taking a GPS reading from a fixed receiver at an exactly known location, then evaluating the error and transmitting it to the vessel, in order to correct its GPS signal. The acoustic position reference system is composed of a subsea acoustic unit (beacon), an acoustic unit (hydrophones) assembled on the platform hull, and a signal processor/computer with an interface to the DPS. Additional information about DGPS, acoustic sensors and other types of displacement sensors can be found in Ryan (2002) and Morgan (1978).

The most common heading sensor is the gyrocompass due its robustness and its proven application in marine systems (Morgan, 1978).

Usually, wind is the only environmental parameter that is measured. Wind speed and direction are measured by an anemometer and the data are used for wind feed-forward control.

The second element of a DPS is the controller. It receives data about displacement, heading and environmental parameters from the sensor system, computes the force and momentum required to counterbalance the environmental loads, and controls thruster action. See the block diagram of DPS in Figure 2.

The third element of a DPS is the thruster system. Its function is to generate the forces and momenta that will counteract the environmental loads and thus keep the platform within the tolerance radius. There are many types of thrusters. According to Morgan (1978), there is not a specific thruster with a better performance for DPS, and the choice is mainly based on the DPS builder's experience with a particular type.

Finally, the fourth element of a DPS is the electrical power generating system. Its choice depends mainly on the number of thrusters and on whether the thrusters are driven by AC or DC motors.

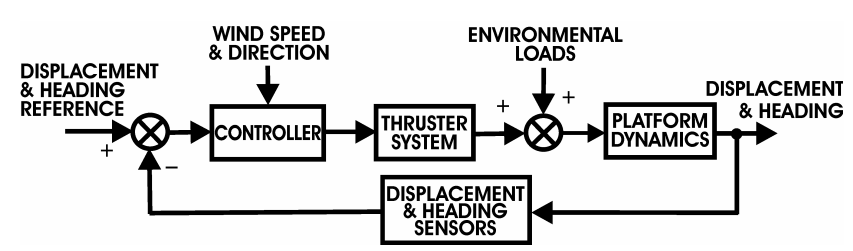

Figure2. A block diagram of DPS.

\section{Equation of Motion for a Floating Platform}

Floating platform dynamics can be modeled as a nonlinear mass-spring-damper system. In this work, the simulation program was coded using the integral-differential equation proposed by Cummins (1962), as shown in Eq.(1).

$$
3(M+m) \ddot{x}+\int_{-\infty}^{\infty} K(t-\tau) \cdot \dot{x}(\tau) d \tau+B \cdot|\dot{x}| \cdot \dot{x}+c \cdot x=F_{T}
$$

The constant added mass and the impulse response function are calculated by Eq.(2) and Eq.(3).

$$
\begin{gathered}
m=a(\omega)+\frac{1}{\omega} \cdot \operatorname{Im}\left[\int_{-\infty}^{\infty} K(\tau) \cdot e^{i \omega t} d t\right] \\
K(t)=\frac{1}{2 \pi} \int_{-\infty}^{\infty} b(\omega) \cdot e^{-i \omega t} d \omega
\end{gathered}
$$

\section{Environmental Forces} Eq.(4).

The Current and Wind loads can be modeled as drag force, as in

$$
F_{c / w}=\frac{1}{2} \cdot \rho \cdot C_{D} \cdot A \cdot|V-\dot{x}| \cdot(V-\dot{x})
$$

In the present paper, a simplification was assumed: the platform was meshed into elementary shapes in order to evaluate the overall platform drag coefficient (DnV, 1977). However, interaction of wakes and vortices with columns and pontoons can be considerable, and influences the drag coefficient. Developments on this topic are available in the literature (Meneghini et al., 2001; Oliveira and Sphaier, 2001). Usually, for platform system design, experiments are often carried out with models in a wind tunnel, water current and wave facilities.

Wave loads can be modeled as the first and second terms of the Volterra series (Dalzell, 1974), as shown by Eq. (5).

$$
F(t)=\int_{-\infty}^{\infty} h_{1}(\tau) \cdot \zeta(t-\tau) d \tau+\int_{-\infty}^{\infty} \int_{-\infty}^{\infty} h_{2}\left(\tau_{1}, \tau_{2}\right) \cdot \zeta\left(t-\tau_{1}\right) \cdot \zeta\left(t-\tau_{2}\right) d \tau_{1} d \tau_{2}
$$

Volterra kernels are calculated by means of Eq.(6) and Eq.(7).

$$
\begin{gathered}
h_{1}(t)=\frac{1}{2 \cdot \pi} \int_{-\infty}^{\infty} H_{1}(\omega) \cdot e^{-i \omega t} d \omega \\
h_{2}\left(t_{1}, t_{2}\right)=\frac{1}{(2 \cdot \pi)^{2}} \int_{-\infty}^{\infty} \int_{-\infty}^{\infty} H_{2}\left(\omega_{1}, \omega_{2}\right) \cdot e^{i\left(\omega_{1} t_{1}-\omega_{2} t_{2}\right)} d \omega_{1} d \omega_{2}
\end{gathered}
$$

The first term in Eq.(5) corresponds to the first-order drift force (linear), and the second term corresponds to the second-order drift force (nonlinear). However, the algorithm for Eq.(5) is too timeconsuming, and in order to improve the program performance, 
Newman's approximation was used (Newman, 1974). Eq.(8) is the approximation for the first-order drift force, and Eq.(9) is the approximation for the second-order drift force.

$$
\begin{gathered}
F_{1}(t)=\sum_{j=1}^{N} \zeta_{j} \cdot\left|H_{1}\left(\omega_{j}\right)\right| \cdot \sin \left(\omega_{j} \cdot t+\phi_{1}\left(\omega_{j}\right)\right) \\
F_{2}(t)=2 \cdot\left(\sum_{j=1}^{N} \zeta_{j} \cdot \sqrt{H_{2}\left(\omega_{j}, \omega_{j}\right)} \cdot \cos \left(\omega_{j} \cdot t+\phi_{2}\left(\omega_{j}, \omega_{j}\right)\right)\right)^{2}
\end{gathered}
$$

Equation (5) is replaced by the sum of Eq.(8) and Eq.(9).

\section{Waves}

A regular wave can be modeled as a sinusoidal oscillation about water level, as in Eq.(10).

$$
\zeta(t)=\zeta_{1} \cdot \cos \left(\omega_{1} \cdot t\right)
$$

Following Morooka and Yokoo (1995), irregular waves can be obtained by superposition of regular waves, as in Eq.(11),

$$
\zeta(t)=\sum_{j=1}^{\infty} \zeta_{j} \cdot \cos \left(\omega_{j} \cdot t+\varepsilon_{j}\right)
$$

where,

$$
\zeta_{j}=\sqrt{2 \cdot S\left(\omega_{j}\right) \cdot \Delta \omega}
$$

In this paper, the ISSC (International Ship Structures Congress) Spectrum is used. The ISSC Spectrum is a two parameters spectrum (Chakrabarti, 1994), Eq.(13),

$$
S(\omega)=0.1107 \cdot H_{S}{ }^{2} \cdot \frac{\bar{\omega}^{4}}{\omega^{5}} \cdot \exp \left(-0.4427\left(\bar{\omega} / \omega^{4}\right)\right.
$$

where,

$$
\begin{aligned}
& \bar{\omega}=1.29 \cdot \omega_{0} \\
& \omega_{0}=\frac{2 \cdot \pi}{T_{0}}
\end{aligned}
$$

\section{Thrusters}

Thruster forces can be expressed as a first-order system, as Eq.(16) shows in Time Domain (Zunderdorp and van der Vlies, 1972).

$$
E_{C}(t)=E(t)+\tau \cdot \frac{d E(t)}{d t}
$$

In this work, a time constant of $5.0 \mathrm{~s}$ was adopted. In order to prevent mechanical fatigue of the thruster system, the controller is not allowed to vary the value of the force continuously, but only at intervals of 20s. The reduction of thruster force by current influx is not taken into account in the simulator.

\section{PID Control}

The Proportional-Integral-Derivative (PID) control is a classical feedback control technique. It has 3 terms: the first is proportional to the error signal; the second, to the time integral of the error signal, and the third, to the time derivative of the error signal, as shown in Eq.(17).

$$
u(t)=K_{p} \cdot e(t)+K_{I} \cdot \int_{0}^{t} e(t) \cdot d t+K_{D} \cdot \frac{d e(t)}{d t}
$$

Usually, the error signal is equal to the reference data minus the feedback data, as shown in Figure 3.

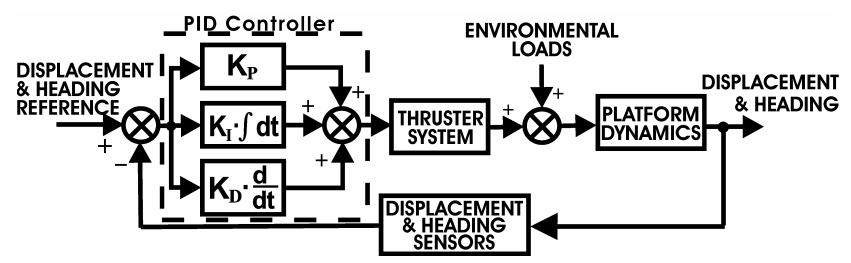

Figure 3. Block diagram of a PID controller.

The PID control algorithm is simple but has a drawback: its 3 gains, $K_{P}, K_{I}$ and $K_{D}$, are difficult to determine. In this paper, the PID controller was tuned using the Ziegler-Nichols method described in Bolton (1995).

\section{Fuzzy Control}

According to Zadeh (1965), a fuzzy controller can use logical rules in the control algorithm, in an attempt to describe, by means of a routine, the experience, intuition and heuristics used by humans to control a process. Conventional controllers, in contrast, use control algorithms described by algebraic or differential equations that are in fact a mathematical model of the process to be controlled. The first application of fuzzy control techniques was with the research and project of Mamdani and Assilian (1975).

The fuzzy controller is composed of a fuzzifier interface, a rule inference interface, a rule base, and a defuzzifier interface. The fuzzifier interface translates the system inputs from the real domain into the fuzzy domain in the form of a linguistic variable. Using the linguistic variables, the rule inference interface infers the IF-THEN rules stored in the rule base. The rule base is a repository of all the knowledge used to control the system. The inference outputs are brought back to the real domain by means of the defuzzifier interface, as shown in Figure 4.

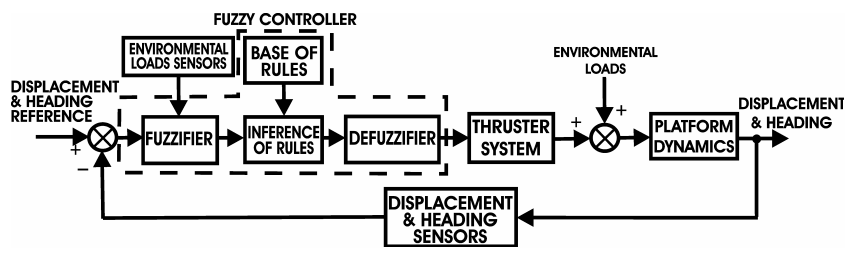

Figure 4. Block diagram of a fuzzy controller.

\section{Linguistic Variable}

A linguistic variable must be defined (Sandri and Correa, 1999), by a quadruple as in Eq.(18):

$$
\left(\mathrm{X}, \Omega, \mathrm{T}(\mathrm{X}), \mathrm{M}_{\mathrm{F}}\right)
$$

An example of a linguistic variable is shown in Figure 5. 


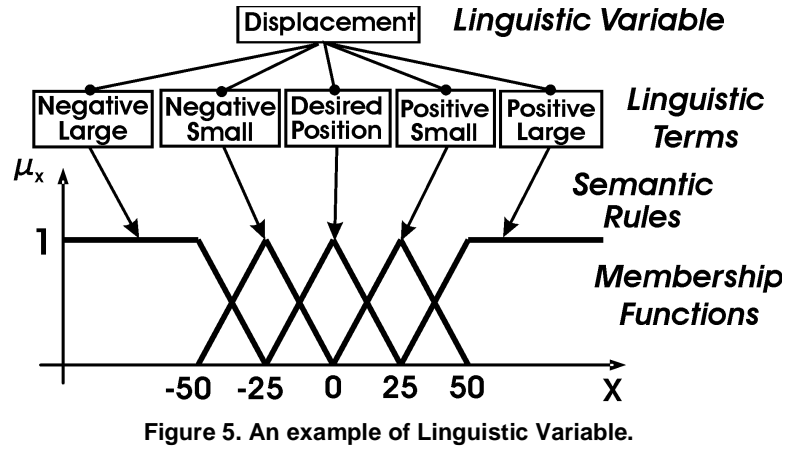

This linguistic variable is called Displacement (X=Displacement), and represents the drift of the floating platform from its desired location. The universe of discourse is the set of all real numbers, $(\Omega \in \Re)$. The set of linguistic terms associated with Displacement are $T($ Displacement $)=\{$ Negative Large, Negative Small, Desired Position, Positive Small, Positive Large\}. Each term has a semantic rule, and each semantic rule is associated to a membership function. In this example, the membership functions have trapezoidal and triangular shapes. Other shapes can be used as membership functions, provided that the functions are normalized in 1.

\section{Fuzzifier Interface}

Before the rules can be inferred, it is necessary to fuzzify the inputs. A displacement of, say, $20 \mathrm{~m}$ is in the real domain, and must be transformed into the fuzzy domain in the form of a linguistic variable, as shown in Figure 5. According to the membership functions (Figure 6), the term Desired Location has a membership degree of 0.2; Positive Small has membership degree of 0.8, and all other terms have a membership degree equal to zero.

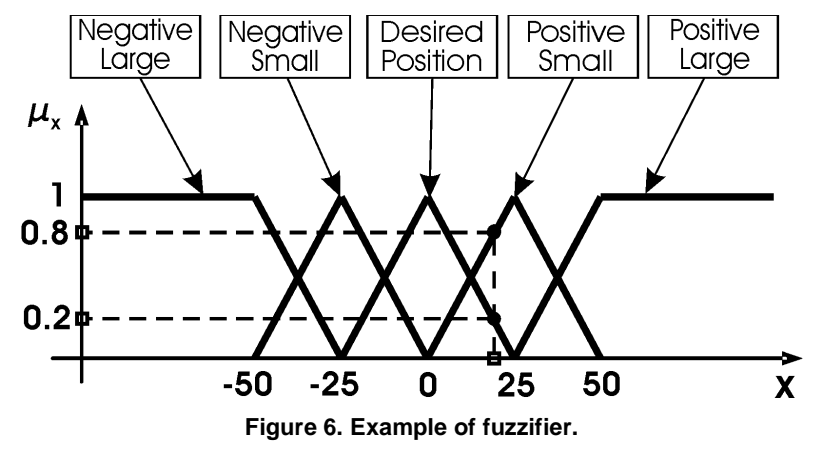

\section{Rule Inference}

The rules used in the fuzzy controller are as shown by Eq.(19):

$$
\mathrm{R}_{\mathrm{i}}: \operatorname{IF}(\langle\alpha\rangle \operatorname{AND}\langle\beta\rangle) \operatorname{THEN}\left\langle\gamma_{\mathrm{i}}\right\rangle
$$

The AND operator expresses the lesser value between the membership degree of $\alpha$-term and of the $\beta$-term, $\min \left(\mu_{\alpha}, \mu_{\beta}\right)$. The THEN operator stores the result of the previous operation in the $\gamma_{\mathrm{i}^{-}}$ output term. The response of the fuzzy controller will be the union of all output terms.

\section{Defuzzifier Interface}

Output linguistic terms and output membership degrees cannot be directly used to govern the action of thrusters; the fuzzy controller output must first be defuzzified. There are several defuzzifier methods, some of which can be found in Simões and Shaw (1999).

In this paper, the Center-of-Area defuzzifier method, also called Center-of-Gravity or Centroid method, was used. It calculates the center of the area formed by the sum of all the output terms of the fuzzy controller. Equation (20) shows the center-of-area equation for the discrete case.

$$
Z_{\text {out }}=\frac{\sum_{i=1}^{N} Z_{i} \cdot \mu_{\text {out }}\left(Z_{i}\right)}{\sum_{i=1}^{N} \mu_{\text {out }}\left(Z_{i}\right)}
$$

Consider for instance, the linguistic variable called Thrust. Figure 7 shows its membership functions. It has two non-zero linguistic terms: Without-Thrust, with membership degree 0.6, and Positive-Medium, with membership degree 0.4. The defuzzified controller output will be the position of the center of gravity of the union of the term areas; in this case, Zout=21.

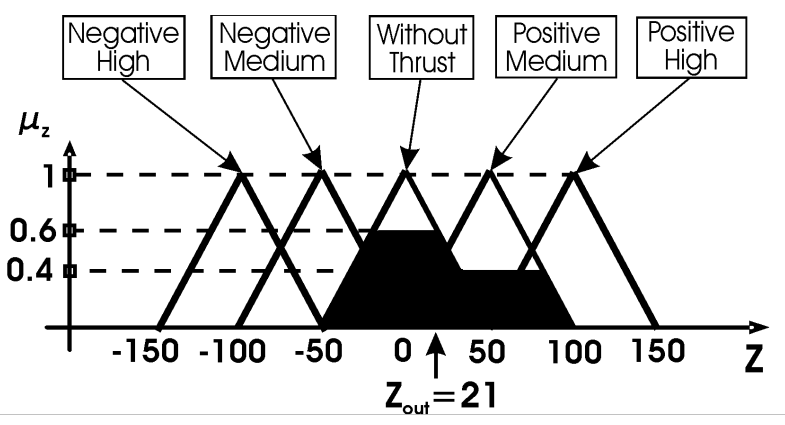

Figure 7. Example of Defuzzifier.

\section{Results}

In this paper, the standard semi-submersible platform adopted for comparative calculations by the International Towing Tank Conference (ITTC) was chosen as a model, due to the availability of information and data about it. All data were obtained from Vardaro (1991).

This semi-submersible platform has two pontoons, each with a length of $115 \mathrm{~m}$, width of $15 \mathrm{~m}$ and height of $8 \mathrm{~m}$. It has a total of eight columns, with diameters of $10 \mathrm{~m}$ for the four external columns, and $8 \mathrm{~m}$ for the four central columns (Figure 8).
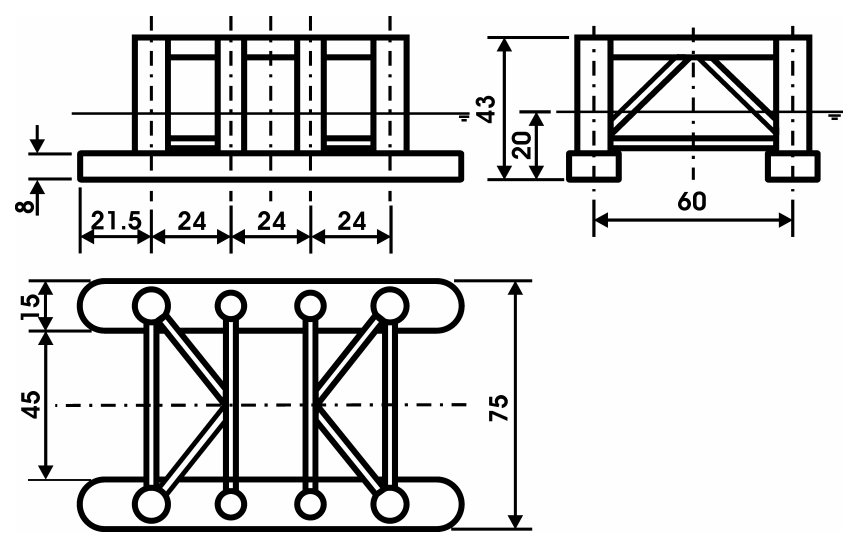

Figure 8. ITTC Platform's dimensions [meters].

Before the DPS simulations, results of the numerical simulator program were compared with results of Vardaro (1991) (Figure 9). 


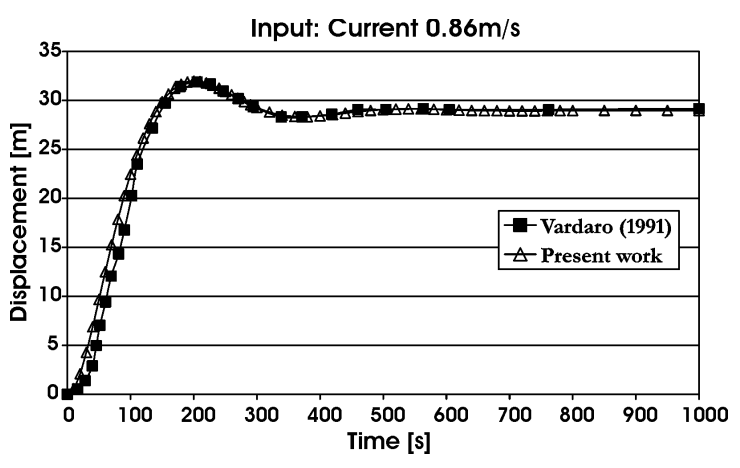

Figure 9. Validation of results.

The small discrepancy observed between these results was caused mainly by a difference in the mathematical modeling of the mooring system. The mooring line was modeled as a nonlinear spring with a coefficient varying exponentially with the displacement. In Vardaro (1991), the selected model was a spring linearized around the operational point - a simplification not adopted in this paper.

Next, the performance of moored platform and platforms with DPS were compared under different environmental loads (Figures 10, 11, 13, and 15). For each simulation, the mooring system and three different DPS controllers were tested: one PID controller and two fuzzy controllers.

This paper presents three distinct fuzzy controllers. The first one is called Fuzzy-PD, and evaluates platform displacement and velocity.

The other two fuzzy controllers can be classified as feedforward controls, because they use data from disturbances (environmental loads) to act on the thrusters before the loads upset the platform behavior (Seborg et all, 1989). The Fuzzy-Cur controller evaluates platform displacement and the square of current velocity; it was only applied to current loads (Figure 10). The Fuzzy-Wave controller evaluates platform displacement and wave height (Figure 11,13 , and 15).

A comparison was carried out among the results of a moored system, a DPS equipped with PID controller and two DPS equipped with Fuzzy-PD and Fuzzy-Cur controller, for a current of $0.86 \mathrm{~m} / \mathrm{s}$ (Figure 10).

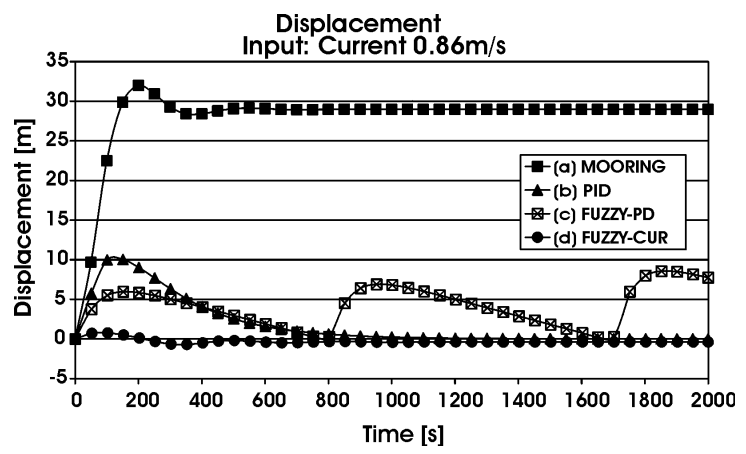

Figure 10. Results for current of $0.86 \mathrm{~m} / \mathrm{s}$.

As shown in Figure 10, the Fuzzy-Cur controller achieved an excellent performance. The Fuzzy-PD controller showed pulsing behavior, because the rules turn off the thrusters when the platform reaches the reference with a very low velocity. The PID Controller had a good performance, since it converged to zero. The anchored system (with no dynamic positioning) had a satisfactory performance, keeping the position to within $30 \mathrm{~m}$ of the reference, thus complying with the original project of the platform's mooring system.

Figure 11 presents the results of the second simulation, under the action of regular waves of $3 \mathrm{~m}$ of height and a period of $9.0 \mathrm{~s}$ (input). The wave heights of the initial $100 \mathrm{~s}$ were attenuated. Four cases were assessed: (a) anchored platform; (b) DPS with PID controller; (c) DPS with Fuzzy-PD; and (d) DPS with Fuzzy-Wave.

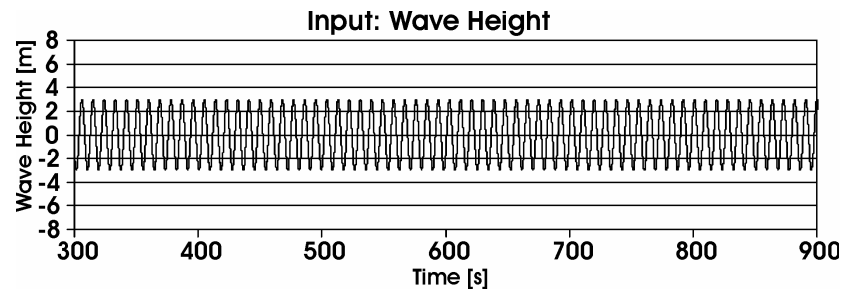

(a) Output: MOORING SYSTEM

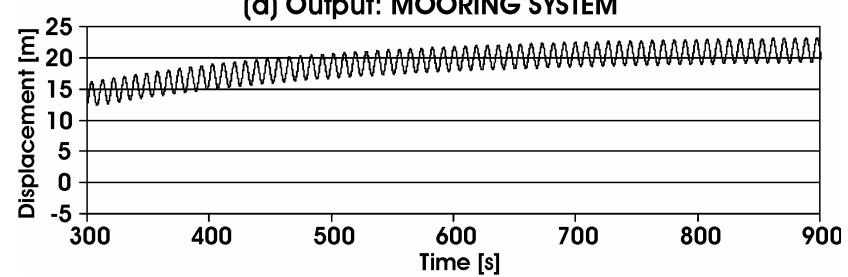

(b) Output: PID

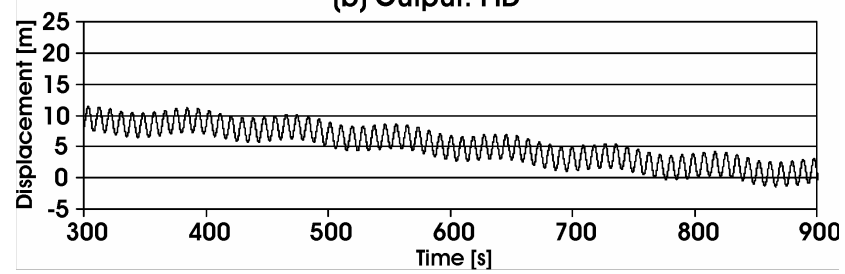

(c) Output: FUZZY-PD

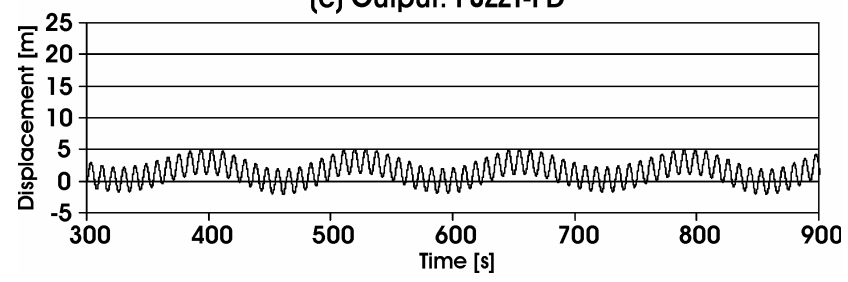

(d) Output: FUZZY-WAVE

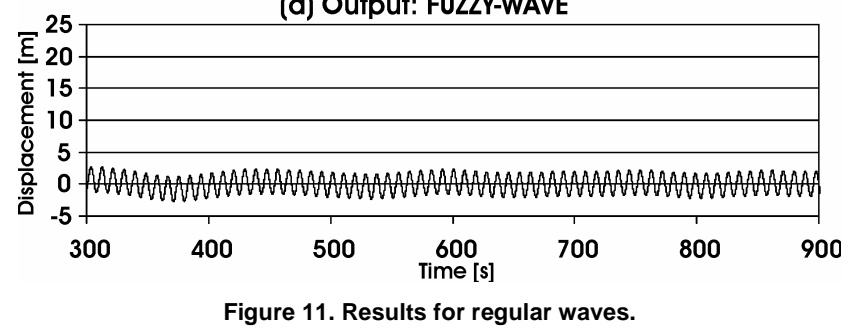

As seen in Figure 11, the Fuzzy-Wave controller attained an excellent performance, whereas the Fuzzy-PD controller continued to display pulsing behavior because of the rule that turns off the thrusters when the platform reaches the desired point. The PID controller had a good performance, converging to the reference. The mooring system performs satisfactorily, keeping the platform within about $20 \mathrm{~m}$ of the origin.

The next two simulations are for irregular waves.

The first irregular wave simulation reflects typical wave conditions in the Campos Basin (Brazil) for a return period of 1 
year. The two parameters for ISSC Spectrum are $\mathrm{H}_{\mathrm{S}}=5.1 \mathrm{~m}$ and $\mathrm{T}_{0}=11 \mathrm{~s}$ (Figure 12).

Using the ISSC spectrum, it is possible to generate irregular waves (input). Then using the Fast Fourier Transform algorithm (Press et al., 1992), the input is converted in spectrum again (Calculated Spectrum of Figure 12) to verify if the irregular waves are compatible with the ISSC Spectrum. After, the simulator calculates the behavior of three DPS equipped with distinct controllers (output). Figure 13 shows this generated irregular wave pattern (input) and the performance of (a) an anchored platform and platforms equipped with three different DPS controllers: (b) PID, (c) Fuzzy-PD, and (d) Fuzzy-Wave. In this simulation, wave heights of the initial $100 \mathrm{~s}$ were attenuated.

The second irregular wave condition represents a typical return period of 10 years in the Campos Basin. Figure 14 shows the ISSC Spectrum; its parameters are $\mathrm{Hs}=6.3 \mathrm{~m}$ and $\mathrm{T} 0=12 \mathrm{~s}$. Wave heights of the initial $100 \mathrm{~s}$ were attenuated.

Figure 15 shows the generated irregular waves (input), and the behavior of moored platform and three DPS equipped with the same three controllers as in the previous simulation.

Results in Figures 13 and 15 the performance of the moored platform and platforms with three DPS equipped with different controllers. The mooring system keeps the platform within $60 \mathrm{~m}$ for a 1 -year return period, and $100 \mathrm{~m}$ for a 10 -year return period. The DPS equipped with PID controller converges to the reference in both results, but the controller does not keep the platform exactly at the reference because the wave loads are irregular and time-variant. The Fuzzy-PD controller has a pulsing behavior because its rules turn off the thrusters when the platform reaches the reference with a low velocity. Finally, the Fuzzy-Wave controller evaluates platform displacement and wave height, and keeps the platform around the reference.

This paper proposes three distinct fuzzy controllers. The first one, Fuzzy-PD, evaluates platform the displacement and velocity. It did not converge to the reference when applied to constant loads (current) and time-varying loads (waves). It displayed pulsing behavior, caused by the rules that turn off the thrusters when the platform reaches the reference with a very low velocity. The second and third types of Fuzzy controllers featured are classified as feedforward controls.

The Fuzzy-Cur feedforward controller evaluates platform displacement and the square of current velocity. It was applied only to current loads, and had the best performance compared to the moored platform and the other DPS controllers (Figure 10).

The Fuzzy-Wave feedforward controller evaluates platform displacement and wave height. It displays its best performance with regular waves (Figure 11), but even with irregular waves its results are as good as the PID controller (Figures 13 and 15).

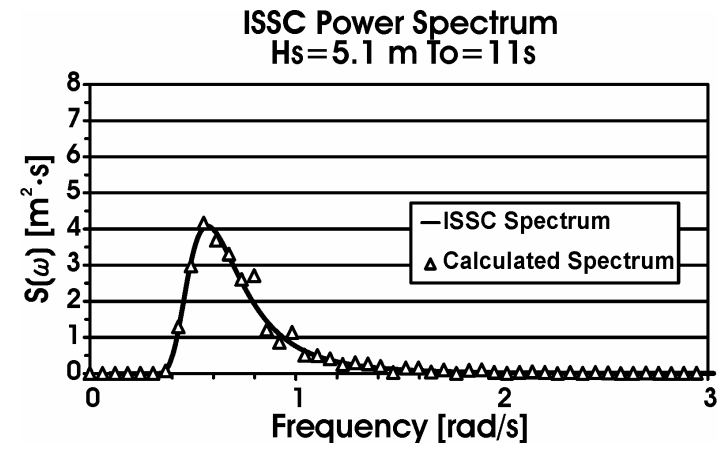

Figure 12. Comparison between ISSC and Measured Spectra.

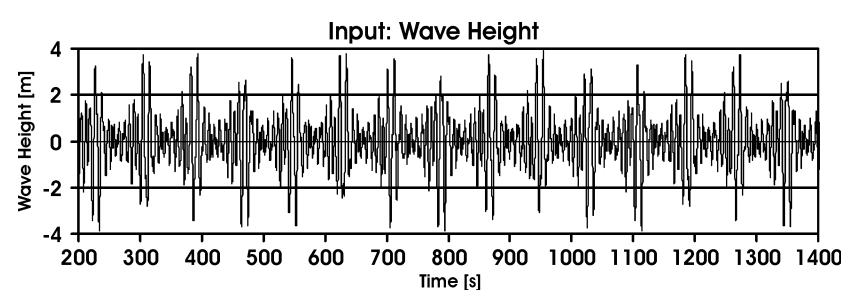

(a) Output: MOORING SYSTEM

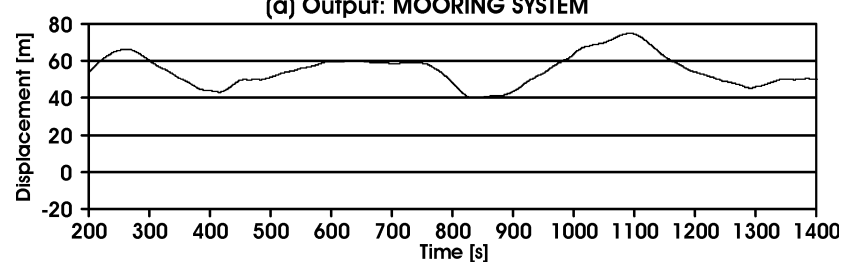

(b) Output: PID

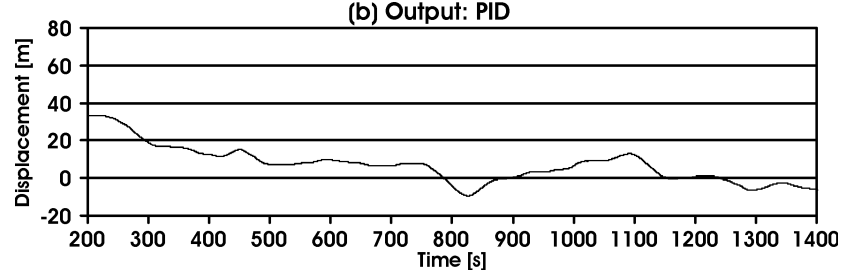

(c) Output: FUZZY-PD

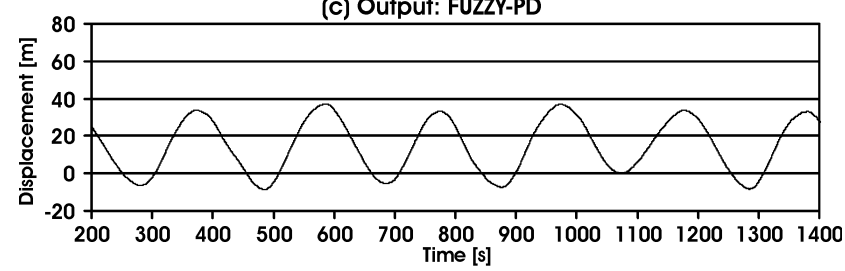

(d) Output: FUZZY-WAVE

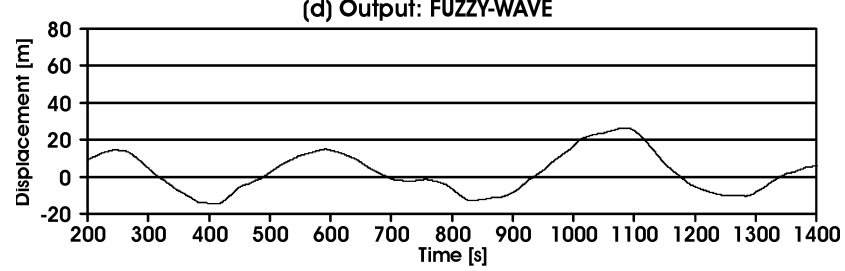

Figure 13. Results of irregular waves for a return period of 1 yea (Hs=5.1m To=11s).

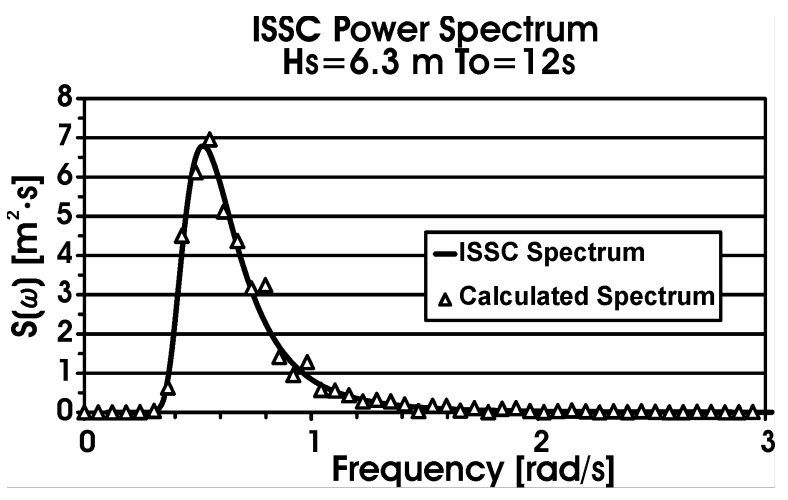

Figure 14. Comparison between ISSC and Measured Spectra. 


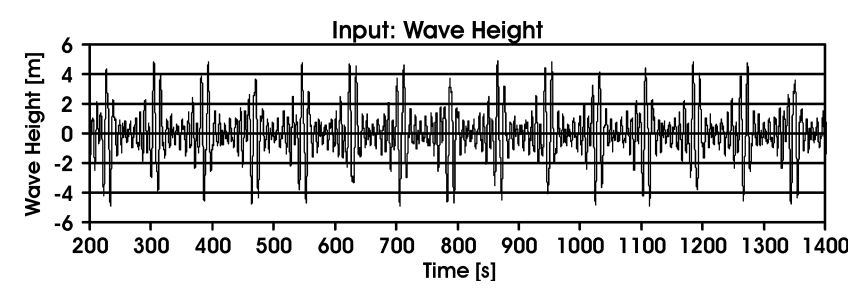

(a) Output: MOORING SYSTEM

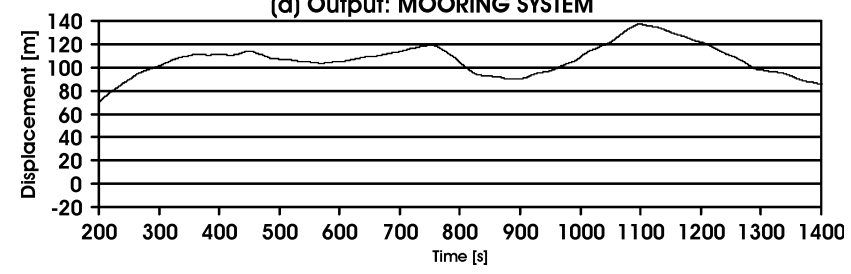

(b) Output: PID

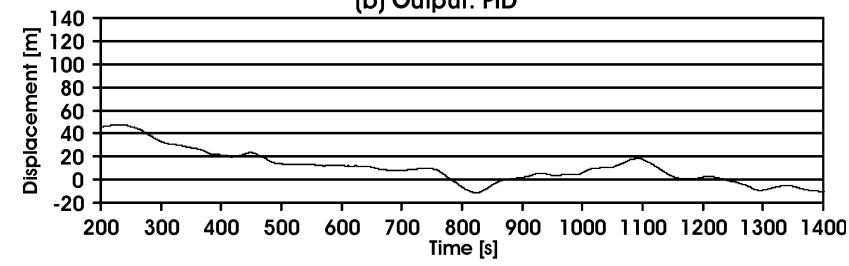

(c) Output: FUZZY-PD
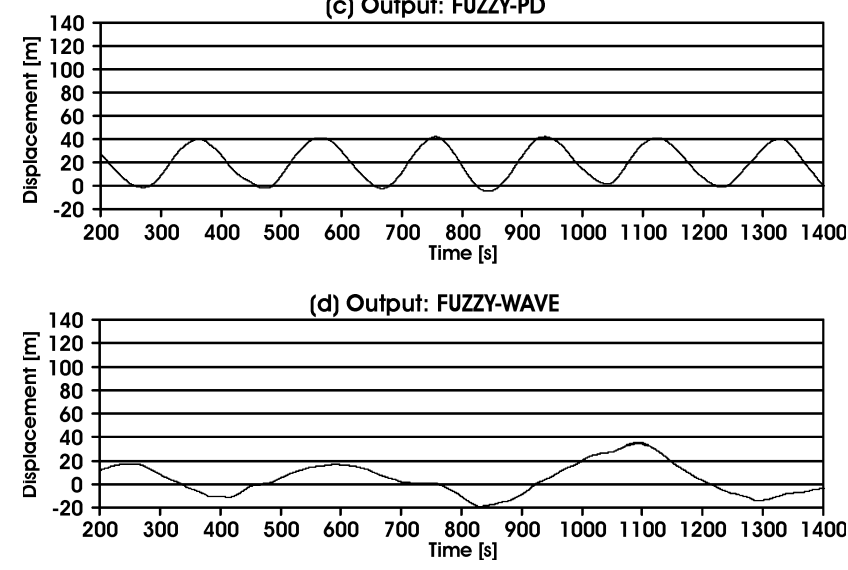

Figure 15. Results to irregular waves for return a period of 10 years (Hs=6.3m To=12s).

\section{Conclusion}

The PID controller displayed a good performance, converging and keeping close to the reference in all simulations. An advantage of the PID controller is the simplicity of the control algorithm, and extensive available literature, including several applications in control engineering. A disadvantage of the PID controller is the difficulty in determining and adjusting the three gains: $\mathrm{K}_{\mathrm{P}}, \mathrm{K}_{\mathrm{I}}$ and $\mathrm{K}_{\mathrm{D}}$.

In the present paper, the possibility of using a fuzzy controller in a Dynamic Positioning System of a floating platform is presented. The main advantages of Fuzzy control are easy controller tuning and easy implementation of the feedforward control principle. There is no need for information about the mass-spring-damper system and load models (disturbance) in order to tune the fuzzy controller; its adjustment is based solely on accumulated expert knowledge about the system.

\section{Acknowledgements}

The authors would like to acknowledge the financial support of FAPESP (The State of São Paulo Research Foundation), Process n. 01/07787-9.

\section{References}

Bolton, W., 1995, "Control Engineering” (In Portuguese), Makron Books, S. Paulo, Brazil.

Chakrabarti, S.K., 1994, "Hydrodynamics of Offshore Structures", Computational Mechanics Publication, London.

Cummins, W.E., 1962, "The Impulse-response Function and Ship Motions”, Schiffstechnik, Vol. 47, no. 9, pp. 101-109.

Dalzell, J.F., 1974, "Cross-Bispectra Analysis: Application to Ship Resistance in Waves", Journal of Ship Research, Vol. 18, no. 1, pp. 62-72.

DnV, 1977, "Rules for the Design Construction and Inspection of Offshore Structures”, Appendix B: Loads, Det Norske Veritas (DnV), Oslo, Norway.

Mandani, E.H., Assilian S., 1975, "An Experiment in Linguistic Synthesis with a Fuzzy Logic Controller", International Journal of ManMachine Studies, Vol. 7, No. 1, pp. 1-13.

Meneghini, J.R., Saltara, F., Siqueira, C.L.R., Ferrari Jr., J.A., 2001 , "Numerical Simulation of Flow Interference between Two Cylinders in Tandem and Side-by-Side Arrangements", Journal of Fluids and Structures, Vol. 15, pp. 327-350.

Morgan, M.J., 1978, "Dynamic Positioning of Offshore Vessels", PPC Books Division, Tulsa.

Morooka, C.K., Yokoo, I.H., 1995, "Numerical Simulation and Spectral Analysis of Irregular Sea Waves", International Society of Offshore and Polar Engineers (ISOPE) Conference.

Newman, J.N., 1974, "Second-order, Slowly-varying Forces on Vessels in Irregular Waves", International Symposium on the Dynamics of Marine Vehicles and Structures in Waves, ed. R. Bishop and W.G. Price, pp. 182186, Mechanical Engineering Publications Ltd., London.

Oliveira, M.C., Sphaier, S., 2001, "Numerical Simulation of Vortex Induced Vibrations in Three Dimensions Using a Hybrid Method", Proceedings of the $20^{\text {th }}$ International Conference on Offshore Mechanics and Arctic Engineering (OMAE Conference), Rio de Janeiro, Brazil.

Press, W.H., Teukolsky, S.A., Vetterling, W.T., Flannery, B.P, 1992 "Numerical Recipes in C - The Art of Scientific Computing", $2^{\text {nd }}$ Ed., Cambridge University Press.

Ryan, S.J., 2002, "Augmentation of DGPS to Marine Navigation", PhD Thesis, University of Calgary, Department of Geomatics Engineering, Alberta, Canada.

Sandri, S., Correa, C., 1999, "Fuzzy Logic" (In Portuguese), V Escola de Redes Neurais, S. Jose dos Campos, SP, Brazil.

Seborg, D.E., Edgar, T.F., Mellichamp, D.A., 1989, "Process Dynamics and Control", John Wiley \& Sons.

Simões, M.G., Shaw, IS., 1999, "Fuzzy Control and Model" (In Portuguese), Ed. Edgar Blücher and FAPESP-The State of São Paulo Research Foundation, S. Paulo, Brazil.

Tannuri, E.A., Donha, D.C., Pesce, C.P., 2001, "Dynamic Positioning of a Turret Moored FPSO Using Sliding Mode Control", International Journal of Robust and Nonlinear Control, Vol. 11, pp. 1239-1256.

Vardaro, E., 1991,"A Study of Motions of a Semi-Submersible Platform through Time Domain Simulation" (In Portuguese), M.Sc. Thesis, State University of Campinas, Campinas, Brazil.

Zadeh, L.A., 1965, "Fuzzy Sets", Information and Control, Vol. 8, pp. 338-353.

Zunderdorp, H.J., van der Vlies, J.A., 1972, "How to Optimise a Dynamic-Stationing System", Society of Petroleum Engineers (SPE), European Spring Meeting, Amsterdam, Netherlands, SPE \#3757. 